\title{
The cardiovascular health of young people with severe mental illness: addressing an epidemic within an epidemic
}

\author{
Sue Bailey, ${ }^{1,2}$ Clare Gerada, $^{3}$ Helen Lester, ${ }^{4}$ David Shiers ${ }^{5}$
}

The Psychiatrist (2012), 36, 375-378, doi: 10.1192/pb.bp.112.039727

${ }^{1}$ Greater Manchester West Mental Health NHS Foundation Trust, Manchester; ${ }^{2}$ University of Central Lancashire; ${ }^{3}$ Hurley Clinic, London; ${ }^{4}$ University of Birmingham; ${ }^{5}$ National Mental Health Development Unit, London

Correspondence to David Shiers (david.shiers@doctors.org.uk)

First received 18 Apr 2012, final revision 19 Jul 2012, accepted 31 Jul 2012

\begin{abstract}
Summary For young people with emerging psychosis, early weight gain and its potential cardiac and metabolic consequences amplify worrying UK public health trends for young people in general. This paper will argue that if clinicians dismiss these changes as of secondary concern in psychiatric treatment for their young patients, they may be inadvertently condoning a first critical step on a path towards physical health inequalities. Greater recognition is needed for this patient population in their 20 s and 30s, at ages not normally considered for active primary or secondary cardiovascular prevention, who are at high risk of dying prematurely. The early phase of psychosis presents an important treatment window for protecting cardiometabolic health.
\end{abstract}

Declaration of interest D.S. received a fee for keynote presentation on early intervention in psychosis with a particular focus on the physical health issues at a Janssen-Cilag educational meeting in 2010. He provides paid consultancy to the National Audit of Schizophrenia by the Royal College of Psychiatrists' Centre for Quality Improvement.

\section{An ounce of prevention is worth a pound of 'cure'}

Let us start with a not infrequent clinical dilemma: a young person recently commenced on antipsychotics walks into a consulting room and is almost unrecognisable because of rapid weight gain. However, their delusions are apparently improving and in that sense the patient is symptomatically improving. Should the clinician be concerned?

\section{A path to health inequality}

Few would argue against the inclusion of physical health as one of the six key ambitions of current government mental health policy: 'Fewer people with mental health problems will die prematurely, and more people with physical ill health will have better mental health'. ${ }^{1}$ Still, substantial numbers of the 7500 people who develop a psychosis each year in England face a future compromised not only by psychological difficulties but also by poor physical health. Recent high-quality evidence suggests that compared with the general population, there is a 20-year mortality gap for men and a 15-year gap for women, an issue described by Professor Thornicroft as a 'scandal of premature mortality that contravenes international conventions for the "right to health". 2 Behind this 'scandal of premature mortality' lies a reality that mental and physical disorders frequently coexist, often intertwined with social exclusion and restricted opportunity, bringing with it all the problems of disadvantage. For instance, approximately $90 \%$ of people with severe mental illness, particularly those with a diagnosis of schizophrenia, are unemployed, many have impoverished social networks, take little exercise, experience poor nutrition and smoke heavily. ${ }^{3}$ In addition to these specific adversities, such patients often have poor access to both primary and secondary healthcare, ${ }^{4}$ a consequence of poor organisation of health services and a failure by doctors across the primary/specialist interface to agree responsibility. ${ }^{5,6}$ The premature mortality gap also appears to be widening. ${ }^{7}$ This may be secondary to population-level increasing rates of cardiovascular disease and type 2 diabetes and compounded by emerging evidence of inequalities in the provision of medical care, particularly for cardiovascular disease, ${ }^{8}$ but also for diabetes and cancer care. $^{9}$

\section{The heart of the problem}

People with severe mental illness are exposed to significant cardiometabolic risk, namely central obesity, glucose dysregulation, dyslipidaemia and metabolic syndrome, and have high rates of smoking. ${ }^{3}$ There is evidence for increased intra-abdominal fat and glucose dysregulation in people with first-episode psychosis even before treatment commences, ${ }^{10}$ but what is striking is how these changes accelerate after initiating antipsychotic treatment. In a study $^{11}$ of 272 treatment-naive young people aged 4-19 years with a range of diagnoses including schizophrenia, the cardiometabolic effects of four commonly prescribed atypical antipsychotics - aripiprazole, olanzapine, quetiapine or risperidone - were observed prospectively for a 12-week 
period. Significant average weight gain occurred for all those treated, ranging between 4.4 and $8.5 \mathrm{~kg}$ for individual drugs, whereas the untreated comparison group gained on average only $0.2 \mathrm{~kg}$. Not only do patients treated with antipsychotic medication gain weight, but they also experience significant increases in total cholesterol, triglycerides and glucose. ${ }^{12}$ Moreover, these adverse effects are common; a third of firstepisode patients had evidence of metabolic disturbance within 8 months of commencing treatment. ${ }^{13}$ Of note, both diabetes and dyslipidaemia can occasionally appear even in the absence of weight gain, underlining the importance clinically of being alert to the possibility of serious metabolic disturbance occurring in those on antipsychotic medication who have not gained weight. ${ }^{14}$

Weight gain and obesity are of particular concern because of their potential to adversely affect cardiometabolic risks. For instance, links between childhood obesity and cardiovascular risks such as dyslipidaemias, glucose intolerance and hypertension are well established ${ }^{15}$ and can explain why childhood obesity predicts coronary heart disease in adulthood. ${ }^{16}$ Thus, it seems likely that significant weight gain in someone with an emerging psychosis may drive the emergence of other cardiometabolic disturbances. However, a lack of critical evaluation of weight gain, specifically in people with a first episode of psychosis, may have obscured the potential impact of antipsychotics. Many of the studies of weight gain involved randomised controlled trials with short follow-up times observing older people with established illness, many of whom may already have gained weight from previous antipsychotic exposure. By contrast, the European First Episode Schizophrenia Trial $\left(\right.$ EUFEST) ${ }^{17}$ is a high-quality study which specifically examined weight gain in a treatment-naive group of firstepisode patients. This study found that the percentage gaining more than $7 \%$ of body weight during the first year of treatment was $86 \%$ for olanzapine, $65 \%$ for quetiapine, $53 \%$ for haloperidol and $37 \%$ for ziprasidone. Citing the findings of this study, Nasrallah ${ }^{18}$ commented: "Neither old antipsychotics, such as haloperidol, nor metabolically "benign" atypicals, such as ziprasidone, are exceptions'. Underlining the differential impact of antipsychotics on a treatmentnaive population, a recent systematic review concluded that weight gain due to antipsychotics had been underestimated three- to fourfold in those with first-episode psychosis. ${ }^{19}$

Rethink Mental Illness, a large UK charity supporting patients with schizophrenia, has recently led a nationwide Commission on Schizophrenia. The findings are yet to be published, but what was striking from the discussions with service users at the Commission meetings is how their expectations, fears and concerns over treatment differ from those of the professionals treating them. These fears are also present in the published evidence. In the 18-month Clinical Antipsychotic Trials for Intervention Effectiveness (CATIE) study, $74 \%$ of patients with established schizophrenia discontinued medication prematurely. ${ }^{20}$ The most commonly cited reasons for discontinuation were patient choice, lack of effect or intolerability of side-effects. To return to the clinical scenario at the start of this paper, it is perhaps now worth reflecting on what might most trouble the young person facing you in the consulting room - the weight gain or the reduction in mental health symptoms.
Most likely it will be the loss of self-esteem and the added stigma that comes with extreme weight gain: ${ }^{21}$ inability to fit into their clothes, run to catch a bus; shame at seeing friends and family because their body shape is out of control. On top of these difficulties, young people may be further distressed by other adverse drug effects such as hyperprolactinaemia (causing menstrual disturbances, sexual dysfunction and galactorrhoea) ${ }^{22}$ and movement disorders. It is hardly surprising then that young people may stop their medicines or default clinic attendance. ${ }^{23}$

\section{An epidemic within an epidemic}

Patients with first-episode psychosis are usually in their teens or early adulthood. Like their peers, they live in a society where increasingly sedentary lifestyles are accompanied by easy access to energy-rich foods. A recent editorial in the British Journal of General Practice emphasises the scale of the problem, ${ }^{24}$ which has witnessed a dramatic rise in rates of obesity in young people over the past 20 years. $^{25}$ The prevalence of type 2 diabetes has increased tenfold in younger people ${ }^{26}$ accompanied by a 14 -fold increase in the incidence of myocardial infarctions. ${ }^{27}$ Given the rapid demographic shift in patterns of obesity, the impact on weight gain for young people with psychosis may be disproportionately greater, adding more evidence to our concern that we are witnessing an epidemic within an epidemic.

\section{A way forward?}

Although clarity over the precise nature and relative contribution of genetics, demographic effects and antipsychotic medicines is still lacking, what is certain is that young people acquire cardiovascular risk factors rapidly in the critical early phase of psychosis. However, this in itself also offers prevention and treatment opportunities.

Over 30 years ago Geoffrey Rose argued for a new 'prevention paradox' to tackle cardiovascular disease, which moves the focus away from simply trying to treat the endpoints of disease to the task of identifying and addressing the underlying causes. ${ }^{28}$ Could a prevention paradox offer people with psychosis a realistic way to tackle this epidemic within an epidemic? There are two tests that the prevention paradox must pass to be considered for implementation feasibility and possibility.

\section{Feasibility test}

Many of the practical building blocks for a more preventive approach are already in place.

(a) The population at risk is well defined and 'known' to specialist services and to primary care through their mental illness registers.

(b) We know when to target prevention - the early critical phase of illness, and in particular the immediate phase around initiation of antipsychotic medicines.

(c) We know the nature of the lifestyle issues that operate (e.g. tobacco smoking, obesity, lack of exercise).

(d) We can identify and track specific modifiable risks (e.g. body mass index (BMI), lipids, glucose, smoking). 
(e) There is good evidence that conditions such as type 2 diabetes and cardiovascular disease can be prevented or delayed by a combination of increased activity, improved diet and weight loss.

(f) Primary care has provided health promotion and disease management programmes for conditions such as heart disease and diabetes for decades, so this way of working is embedded in the fabric of primary care. More recently - since 2006 - the primary care pay-forperformance scheme, the Quality and Outcomes Framework, ${ }^{29}$ has paid general practitioners (GPs) to measure four physical health indicators for people on the primary care mental illness register (people with severe mental illness): BMI (MH12), blood pressure (MH13), total to high-density lipoprotein cholesterol ratio (MH14) and blood glucose (MH15). Currently, the last two indicators are only targeted on those aged over 40 years, missing a key time when such metabolic changes arise and mitigating against good care for these vulnerable young patients. However, this is likely to change as the National Institute for Health and Clinical Excellence (NICE) guidance is updated to reflect the emerging evidence base.

(g) We know how to measure healthcare improvement (e.g. audit, practitioner development, service improvement programmes).

\section{Possibility test}

Encouragingly, systematic cardiometabolic screening and treatment programmes which put equal emphasis on physical well-being from the onset of treatment for psychosis are now emerging. An excellent model recently introduced across New South Wales, Australia, provides a systematic approach for all people with a first episode of psychosis based on an agreed clinical algorithm (Positive Cardiometabolic Health Algorithm, it can be downloaded from the Australian Health Education and Training Institute website: www.heti.nsw.gov.au/cmalgorithm) focused on key cardiovascular risks - weight gain, smoking, lipid and glucose abnormalities, hypertension, awareness of family history of cardiovascular disease or diabetes. ${ }^{30}$

Prevention of weight gain from the commencement of antipsychotics is fundamental. There is evidence of a positive impact from lifestyle interventions (cognitivebehavioural therapy, exercise and diet) on attenuating weight gain for people with first-episode psychosis. ${ }^{31}$ The impact of key individual vulnerabilities should also be thought about. ${ }^{32}$ Evidence from treating people with both schizophrenia and type 2 diabetes has demonstrated the importance of providing reinforcing lifestyle interventions over time by conveying simple consistent messages on complex topics such as cooking skills and meal planning, and incorporating memory aids. ${ }^{33}$ Frequent monitoring can predict which patients are likely to gain weight quickly. ${ }^{34}$ Evidence of early rapid weight gain (e.g. $5 \mathrm{~kg}$ within the first 3 months) or cardiometabolic blood disturbance should prompt an urgent review of antipsychotic medication as switching antipsychotic medicine may reduce these adverse effects. ${ }^{35}$

The dominance of antipsychotic treatments as the automatic first-line approach could also be challenged. ${ }^{36,37}$ A patient-centred choice would include being offered a full menu of evidence-based treatments as well as medication, such as psychological and family interventions. Patients and their families require clear and consistent information to be able to understand and weigh up the benefits and risks of antipsychotic medication, emphasising the trade-offs of improved mental health symptoms $v$. increased risks to physical health. Decisions should be negotiated and fit within the aspirations and values of the individual. ${ }^{38}$

New opportunities for pharmacological interventions should be investigated. For example, metformin has been prescribed for type 2 diabetes over 60 years and has established clinical efficacy and safety. Its use off label has successfully delayed or prevented the onset of diabetes in people with pre-diabetes (biochemically established glucose impairment). Its ability to attenuate weight gain and potentially prevent diabetes is now attracting attention in terms of the treatment of people with severe mental illness. $^{39}$ This is reflected in new NICE guidance on preventing type 2 diabetes, ${ }^{40}$ which includes a recommendation that for vulnerable groups such as those with severe mental illness who have pre-diabetes, metformin could be considered if lifestyle modification has failed to control glucose impairment.

A collaborative framework for considering the impact of antipsychotic use on cardiovascular risk has been set out in a new clinical resource developed by the Royal College of General Practitioners and the Royal College of Psychiatrists through the National Audit of Schizophrenia initiative. ${ }^{41}$

\section{Concluding remarks}

Problematic weight gain and its potential cardiac and metabolic effects can become established within weeks of antipsychotic treatment initiation. As GPs and psychiatrists, our medical training and our role in prescribing give us a unique responsibility to actively intervene to promote physical well-being and protect cardiometabolic health for the thousands of young people with severe mental illness. This prevention paradox is key to improving the physical health of young people with psychosis, particularly those on antipsychotic medication, and addressing, in the longer term, the current 'scandal of premature mortality'.

\section{Acknowledgements}

Special thanks to Dr Jackie Curtis, consultant psychiatrist, and Dr Katherine Samaras, Professor of Endocrinology, for the inspiration of their Early Intervention in Psychosis service development in Sydney, New South Wales, and their ongoing encouragement and sharing of ideas.

\section{About the authors}

Professor Sue Bailey MBChB, FRCPsych, President of the Royal College of Psychiatrists, consultant child and adolescent forensic psychiatrist, Greater Manchester West Mental Health NHS Foundation Trust, and Professor of Child and Adolescent Mental Health, University of Central Lancashire. Dr Clare Gerada FRCP, FRCGP, FRCPsych, Chair of Council, Royal College of General Practitioners, and GP partner, Hurley Clinic, London. Professor Helen Lester MB ChB, MA, MD, FRCGP, Professor of Primary Care, Birmingham University. Dr David Shiers MB ChB, MRCP (UK), retired GP, Leek, North Staffordshire, former joint lead on National Early Intervention in Psychosis programme of National Mental Health Development Unit (2004-2010). 


\section{References}

1 HM Government. No Health without Mental Health: Delivering Better Mental Health Outcomes for People of All Ages. Department of Health, 2011.

2 Thornicroft G. Physical health disparities and mental illness: the scandal of premature mortality. Br J Psychiatry 2011; 199: 441-2.

3 McCreadie RG. Diet, smoking and cardiovascular risk in people with schizophrenia. Descriptive study. Br J Psychiatry 2003; 183: 534-9.

4 Newcomer J, Hennekens JH. Severe mental illness and risk of cardiovascular disease. JAMA 2007; 298: 1794-6.

5 Leucht S, Corves C, Arbter D, Engel RR, Li C, Davis JM. Secondgeneration versus first-generation antipsychotic drugs for schizophrenia: a meta-analysis. Lancet 2009; 373: 31-41.

6 Tiihonen J, Lönnqvist J, Wahlbeck K, Klaukka T, Niskanen L, Tanskanen A, et al. No mental health without physical health. Lancet 2011; 377: 611.

7 Saha S, Chant D, McGrath J. A systematic review of mortality in schizophrenia: is the differential mortality gap worsening over time? Arch Gen Psychiatry 2007; 64: 1123-31.

8 Manderbacka K, Arffman M, Sund R, Haukka J, Keskimäki I, Wahlbeck K. How does a history of psychiatric hospital care influence access to coronary care: a cohort study. BMJ Open 2012; 2: e000831.

9 Mitchell AJ, Malone D, Doebbeling CC. Quality of medical care for people with and without comorbid mental illness and substance misuse: systematic review of comparative studies. Br J Psychiatry 2009; 194: 491-9.

10 Ryan MC, Collins $\mathrm{P}$, Thakore JH. Impaired fasting glucose and elevation of cortisol in drug-naïve first-episode schizophrenia. Am J Psychiatry 2003; 160: 284-9.

11 Correll CU, Manu P, Olshanskiy V, Napolitano B, Kane JM, Malhotra AK. Cardiometabolic risk of second-generation antipsychotic medications during first-time use in children and adolescents. JAMA 2009; 302: 1765-73

12 Foley D, Morley KI. Systematic review of early cardiometabolic outcomes of the first treated episode of psychosis. Arch Gen Psychiatry 2011; 68: 609-16.

13 Curtis J, Henry C, Watkins A, Newall H, Samaras K, Ward P. Metabolic abnormalities in an early psychosis service: a retrospective, naturalistic cross-sectional study. Early Interv Psychiatry 2011; 5: 108-14.

14 Mclntyre RS, McCann SM, Kennedy SH. Antipsychotic metabolic effects: weight gain, diabetes mellitus, and lipid abnormalities. Can J Psychiatry 2001; 46: 273-81.

15 Weiss R, Dziura J, Burgert TS, Tamborlane WV, Taksali SE, Yeckel CW. Obesity and the metabolic syndrome in children and adolescents. N Engl J Med 2004; 350: 2362-74.

16 Baker JL, Olsen LW, Sørensen TI. Childhood bodymass index and the risk of coronary heart disease in adulthood. N Engl J Med 2007; 357: 2329-37.

17 Kahn RS, Fleischhacker WW, Boter H, Davidson M, Vergouwe Y, Keet IP, et al. Effectiveness of antipsychotic drugs in first-episode schizophrenia and schizophreniform disorder: an open randomised clinical trial. Lancet 2007; 371: 1085-97.

18 Nasrallah HA. Folie en masse! It's so tempting to drink the Kool-Aid. Curr Psychiatry 2011; 10: 3.

19 Alvarez-Jimenez M, Gonzalez-Blanch C, Crespo-Facorro B, Hetrick SE, Rodríguez-Sánchez JM, Pérez-Iglesias $\mathrm{R}$, et al. Antipsychotic-induced weight gain in chronic and first episode psychotic disorders - a systematic critical reappraisal. CNS Drugs 2008; 22: 547-62.

20 Lieberman JA, Stroup TS, McEvoy JP, Swartz MS, Rosenheck RA, Perkins DO, et al. Effectiveness of antipsychotic drugs in patients with chronic schizophrenia. N Engl J Med 2005; 353: 1209-23.

21 Vancampfort D, Probst M, Sweers K, Maurissen K, Knapen J, De Hert M. Relationships between obesity, functional exercise capacity, physical activity participation and physical self-perception in people with schizophrenia. Acta Psychiatr Scand 2011; 123: 423-30.
22 Fedorowicz VJ, Fombonne E. Metabolic side effects of atypical antipsychotics in children: a literature review. J Psychopharmacol 2005; 19: 533-50.

23 Hack S, Chow B. Paediatric psychotropic medication compliance: a literature review and research-based suggestions for improving treatment compliance. J Adolesc Psychopharmacol 2001; 11: 59-67.

24 Yates T, Davies MJ, Khunti K. Obesity and chronic disease in younger people: an unfolding crisis. Br J Gen Pract 2012; 62: 4-5.

25 Joint Health Surveys Unit of the National Centre for Social Research, Department of Epidemiology and Public Health University College London Medical School. Health Survey for England -2009: Health and Lifestyles. NSH Information Centre, 2010 (http://www.ic.nhs.uk/pubs/ hse09report).

26 Wilmot EG, Davies MJ, Yates T, Benhalima K, Lawrence IG, Khunti K. Type 2 diabetes in younger adults: the emerging UK epidemic. Postgrad Med J 2010; 86: 711-8.

27 Hillier TA, Pedula KL. Complications in young adults with early-onset type 2 diabetes: losing the relative protection of youth. Diab Care 2003; 26: 2999-3005

28 Rose G. Strategy of prevention: lessons from cardiovascular disease. Br Med J (Clin Res Ed) 1981; 282: 1847-51.

29 NHS Employers, British Medical Association. Quality and Outcomes Framework Guidance for GMS Contract 2011/12: Delivering Investment in General Practice. NHS Employers, 2011 (http://www.nhsemployers.org/ SiteCollectionDocuments/QOFguidanceGMScontract_2011_12 FL\%2013042011.pdf).

30 Curtis J, Newall H, Samaras K. The heart of the matter: cardiometabolic care in youth with psychosis. Early Interv Psychiatry 2012; 6: 347-53.

31 Álvarez-Jiménez M, Hetrick SE, González-Blanch C, Gleeson JF, McGorry PD. Non-pharmacological management of antipsychoticinduced weight gain: systematic review and meta-analysis of randomised controlled trials. Br J Psychiatry 2008; 193: 101-7.

32 El-Mallakh P. Doing my best: poverty and self-care among individuals with schizophrenia and diabetes mellitus. Arch Psychiatr Nurs 2007; 21: 49-60.

33 Cimo A Stergiopoulos E, Cheng C, Bonato S, Dewa C. Effective lifestyle interventions to improve type II diabetes self-management for those with schizophrenia or schizoaffective disorder: a systematic review. BMC Psychiatry 2012; 12: 24

34 Holt RI, Abdelrahman T, Hirsch M, Dhesi Z, George T, Blincoe T, et al. The prevalence of undiagnosed metabolic abnormalities in people with serious mental illness. J Psychopharmacol 2010; 24: 867-73.

35 Weiden PJ. Switching antipsychotic medications: not enough, too often, or just right? Am J Psychiatry 2011; 168: 9.

36 Morrison AP, Hutton P, Shiers D, Turkington D. Antipsychotics: is it time to introduce patient choice? Br J Psychiatry 2012; 201: 83-4.

37 Morrison AP, Hutton P, Wardle M, Spencer H, Barratt S, Brabban A, et al. Cognitive therapy for people with a schizophrenia spectrum diagnosis not taking antipsychotic medication: an exploratory trial. Psychol Med 2012; 42: 1049-56.

38 Fulford KW. Bringing together values-based and evidence-based medicine: UK Department of Health initiatives in the 'personalization' of care. J Eval Clin Pract 2011; 17: 341-3.

39 Newall H, Myles N, Ward P, Samaras K, Shiers D, Curtis J. Efficacy of metformin for prevention of weight gain in psychiatric populations: a review. Int Clin Psychopharmacol 2012; 27: 69-75.

40 National Institute for Health and Clinical Excellence. Preventing Type 2 Diabetes - Risk Identification and Interventions for Individuals at High Risk. NICE, 2012.

41 Lester H, Shiers DE, Rafi I, Cooper SJ, Holt RIG. Positive Cardiometabolic Health Resource: An Intervention Framework for Patients with Psychosis on Antipsychotic Medication. Royal College of Psychiatrists Centre for Quality Improvement, 2012, in press. 